\title{
Video Article \\ Efficient Derivation of Human Cardiac Precursors and Cardiomyocytes from Pluripotent Human Embryonic Stem Cells with Small Molecule Induction
}

\author{
Xuejun H. Parsons ${ }^{1,2}$, Yang D. Teng ${ }^{3,4}$, James F. Parsons ${ }^{1,2}$, Evan Y. Snyder ${ }^{1,2,5}$, David B. Smotrich ${ }^{1,2,6}$, Dennis A. Moore ${ }^{1,2}$ \\ ${ }^{1}$ San Diego Regenerative Medicine Institute \\ ${ }^{2}$ Xcelthera \\ ${ }^{3}$ Department of Neurosurgery, Harvard Medical School \\ ${ }^{4}$ Division of SCI Research, VA Boston Healthcare System \\ ${ }^{5}$ Program in Stem Cell \& Regenerative Biology, Sanford-Burnham Medical Research Institute \\ ${ }^{6}$ La Jolla IVF
}

Correspondence to: Xuejun H. Parsons at parsons@SDRMI.org

URL: https://www.jove.com/video/3274

DOI: doi:10.3791/3274

Keywords: Developmental Biology, Issue 57, human embryonic stem cell, human, cardiac progenitor, cardiomyocytes, human pluripotent cell, cardiac differentiation, small molecule induction, cell culture, cell therapy

Date Published: 11/3/2011

Citation: Parsons, X.H., Teng, Y.D., Parsons, J.F., Snyder, E.Y., Smotrich, D.B., Moore, D.A. Efficient Derivation of Human Cardiac Precursors and Cardiomyocytes from Pluripotent Human Embryonic Stem Cells with Small Molecule Induction. J. Vis. Exp. (57), e3274, doi:10.3791/3274 (2011).

\section{Abstract}

To date, the lack of a suitable human cardiac cell source has been the major setback in regenerating the human myocardium, either by cellbased transplantation or by cardiac tissue engineering ${ }^{1-3}$. Cardiomyocytes become terminally-differentiated soon after birth and lose their ability to proliferate. There is no evidence that stem/progenitor cells derived from other sources, such as the bone marrow or the cord blood, are able to give rise to the contractile heart muscle cells following transplantation into the heart ${ }^{1-3}$. The need to regenerate or repair the damaged heart muscle has not been met by adult stem cell therapy, either endogenous or via cell delivery ${ }^{1-3}$. The genetically stable human embryonic stem cells ( $\mathrm{hESCs}$ ) have unlimited expansion ability and unrestricted plasticity, proffering a pluripotent reservoir for in vitro derivation of large supplies of human somatic cells that are restricted to the lineage in need of repair and regeneration ${ }^{4,5}$. Due to the prevalence of cardiovascular disease worldwide and acute shortage of donor organs, there is intense interest in developing hESC-based therapies as an alternative approach. However, how to channel the wide differentiation potential of pluripotent hESCs efficiently and predictably to a desired phenotype has been a major challenge for both developmental study and clinical translation. Conventional approaches rely on multi-lineage inclination of pluripotent cells through spontaneous germ layer differentiation, resulting in inefficient and uncontrollable lineage-commitment that is often followed by phenotypic heterogeneity and instability, hence, a high risk of tumorigenicity ${ }^{6-8}$ (see a schematic in Fig. 1A). In addition, undefined foreign/animal biological supplements and/or feeders that have typically been used for the isolation, expansion, and differentiation of hESCs may make direct use of such cell-specialized grafts in patients problematic ${ }^{9-11}$. To overcome these obstacles, we have resolved the elements of a defined culture system necessary and sufficient for sustaining the epiblast pluripotence of hESCs, serving as a platform for de novo derivation of clinicallysuitable hESCs and effectively directing such hESCs uniformly towards clinically-relevant lineages by small molecules ${ }^{12}$ (see a schematic in Fig. 1B). After screening a variety of small molecules and growth factors, we found that such defined conditions rendered nicotinamide (NAM) sufficient to induce the specification of cardiomesoderm direct from pluripotent hESCs that further progressed to cardioblasts that generated human beating cardiomyocytes with high efficiency (Fig. 2). We defined conditions for induction of cardioblasts direct from pluripotent hESCs without an intervening multi-lineage embryoid body stage, enabling well-controlled efficient derivation of a large supply of human cardiac cells across the spectrum of developmental stages for cell-based therapeutics.

\section{Video Link}

The video component of this article can be found at https://www.jove.com/video/3274/

\section{Protocol}

\section{Solution and Media Preparation}

1. Gelatin coating solution: $0.1 \%(\mathrm{w} / \mathrm{v})$ gelatin in $\mathrm{ddH}_{2} \mathrm{O}$, autoclaved and store at $4^{\circ} \mathrm{C}$

2. Matrigel coating solutions. Stock solution: slow thaw Matrigel $(10 \mathrm{ml})$ at $4^{\circ} \mathrm{C}$ overnight, add $10 \mathrm{ml}$ ice-cold DMEM or DMEM/F12, mix well and aliquot $1 \mathrm{ml} /$ tube underneath sterilized tissue culture hood, store at $-20^{\circ} \mathrm{C}$. Working solution: slow thaw $1 \mathrm{ml} \mathrm{Matrigel} \mathrm{aliquot} \mathrm{at} 4{ }^{\circ} \mathrm{C}$ for $1-2$ hour, transfer to $14 \mathrm{ml}$ chilled DMEM or DMEM/F12 and mix well underneath sterilized tissue culture hood immediately before coating.

3. Human laminin coating solution: dilute $1 \mathrm{ml}$ human laminin solution $\left(0.5 \mathrm{mg} / \mathrm{ml}\right.$ in Tris Buffered $\mathrm{NaCl}$, store at $-80^{\circ} \mathrm{C}$, slow thaw at $4{ }^{\circ} \mathrm{C}$ for $1-2$ hour) with ice-cold DMEM or DMEM/F12 to $12.5 \mathrm{ml}$ working solution $(40 \mu \mathrm{g} / \mathrm{ml})$ underneath sterilized tissue culture hood immediately before coating. 
4. Growth factor stock solutions (500-1000X): dissolve growth factor at $10 \mu \mathrm{g} / \mathrm{ml}$ in sterilized buffer $(0.5 \% \mathrm{BSA}, 1.0 \mathrm{mM} \mathrm{DTT}, 10 \% \mathrm{glycerol}$, 1XPBS) and store as $50-100 \mu \mathrm{l} /$ tube aliquots at $-80^{\circ} \mathrm{C}$.

5. HESC media: DMEM/F12 or KO-DMEM (80\%), KO serum replacement (20\%), L-alanyl-L-gln or L-gln (2 mM), MEM nonessential amino acids (MNAA, 1X), and $\beta$-Mercaptoethanol $(100 \mu \mathrm{M})$, filtered and store at $4^{\circ} \mathrm{C}$, supplemented with $20 \mathrm{ng} / \mathrm{ml} \mathrm{bFGF}$ before use. Or replacing "KO serum replacement" with defined components: DMEM/F12 or KO-DMEM (100\%), L-alanyl-L-gln or L-gln (2 mM), MNAA (1X), MEM essential amino acids (MEAA, $1 \mathrm{X})$, and $\beta$-Mercaptoethanol $(100 \mu \mathrm{M})$, filtered and store at $4^{\circ} \mathrm{C}$, supplemented with bFGF $(20 \mathrm{ng} / \mathrm{ml})$, human insulin $(20$ $\mu \mathrm{g} / \mathrm{ml})$, ascorbic acid $(50 \mu \mathrm{g} / \mathrm{ml})$, human activin A (50 $\mathrm{ng} / \mathrm{ml})$, human albumin/Albumax $(10 \mathrm{mg} / \mathrm{ml})$, and human transferrin (8 $\mu \mathrm{g} / \mathrm{ml}) \mathrm{before}$ use.

6. HESC cardiac differentiation media: DMEM/F12 (90\%), defined FBS (10\%), and L-alanyl-L-gln or L-gln (2 mM).

7. Media containing nicotinamide (NAM): add NAM to HESC media or HESC cardiac differentiation media to final concentration of $10 \mathrm{mM}$, filtered, store at $4^{\circ} \mathrm{C}$ and use within 2 weeks of preparation.

\section{Plate Coating}

1. Coat plates with gelatin: add $2.5 \mathrm{ml} /$ well of gelatin solution to 6 well plates and incubate overnight in a $37^{\circ} \mathrm{C}$ humidified incubator.

2. Coat plates with laminin: chill gelatin-coated plates and remove gelatin, add $2.5 \mathrm{ml} /$ well Matrigel or human laminin coating working solution to pre-chilled gelatinized 6 -well plates and incubate at $4^{\circ} \mathrm{C}$ overnight.

\section{Passaging and Seeding Undifferentiated hESCs under Defined Conditions}

1. Allow hESC colonies grow to 5-7 days old, and take hESC culture plate to dissecting microscope (pre-warm dissecting stage to $37^{\circ} \mathrm{C}$ ) underneath dissecting sterilized hood.

2. Select hESC colonies to be split. Morphologically, these colonies should have $>75 \%$ undifferentiated hESCs (small compact cells), usually slightly opaque (not white-piled-up cells, not clear-differentiated cells) with defined edge underneath the dissecting microscope. Carefully outline the selected colonies and remove differentiated fibroblast layer surrounding the colony and all differentiated parts (if any) of the colony with the edge of P2 sterile pipette tip or pulled glass capillary.

3. Remove the old media containing floating detached differentiated cells by aspirating. Wash with hESC media (without bFGF) once. Add $3 \mathrm{ml} /$ well fresh hESC media containing $20 \mathrm{ng} / \mathrm{ml} \mathrm{bFGF}$.

4. Cut the undifferentiated hESC colonies into small pieces, and detach with sterile pipette tip or pulled glass capillary.

5. Pool the media containing detached colony pieces together in a $50 \mathrm{ml}$ conical tube. Wash the plate once with $1 \mathrm{ml} / \mathrm{well} \mathrm{hESC}$ media containing $20 \mathrm{ng} / \mathrm{ml} \mathrm{bFGF}$ and pool together.

6. Aspirate the Matrigel or human laminin solution from the coated fresh plates. Aliquot $4 \mathrm{ml} /$ well $\mathrm{hESC}$ media containing colony pieces to a 6 well plate. Gently transfer the plate to incubator without shaking and allow colony pieces seed overnight without disturbing in a humidified $37^{\circ} \mathrm{C}$ incubator with an atmosphere of $5 \% \mathrm{CO}_{2}$.

\section{Cardiac Induction of hESCs under Defined Culture System with Nicotinamide}

1. At day 3 after seeding, remove most of old media from each well of the plate and leave enough media to allow hESC colonies to be submerged (never allow hESCs to dry out). Replace with $4 \mathrm{ml} /$ well fresh hESC media containing $20 \mathrm{ng} / \mathrm{ml} \mathrm{bFGF}$ and $10 \mathrm{mM}$ nicotinamide (NAM).

2. Replace old media with fresh hESC media containing $20 \mathrm{ng} / \mathrm{ml} \mathrm{bFGF}$ and $10 \mathrm{mM}$ NAM every other day, and allow cardiac-induced hESC colonies grow to day 8-10. Upon exposing to NAM, all the cells within the colony will undergo morphology changes to large differentiated cells that will continue to multiply. The colonies will increase in size, and by day $8-10$, and cells will begin to pile up in some areas of the colonies.

\section{Continuing Cardiac Differentiation in Suspension Culture}

1. Take hESC culture plate to dissecting microscope (pre-warm dissecting stage to $37^{\circ} \mathrm{C}$ ) underneath dissecting sterilized hood. Carefully outline the colonies and remove fibroblast layer surrounding the colony (differentiated cells migrated out of the colony) with the edge of P2 sterile pipette tip or pulled glass capillary.

2. Remove the old media containing floating detached fibroblast cells by aspirating. Wash with hESC media (without bFGF) once. Add $3 \mathrm{ml} /$ well fresh hESC media (without bFGF).

3. Cut the cardiac-induced hESC colonies into small pieces, and detach with sterile pipette tip or pulled glass capillary.

4. Pool the media containing detached colony pieces together in a $50 \mathrm{ml}$ conical tube. Wash the plate once with $1 \mathrm{ml} /$ well $\mathrm{hESC}$ media (without bFGF) and pool together.

5. Aliquot $4 \mathrm{ml} /$ well serum-free hESC media containing colony pieces to a 6 -well ultralow attachment plate and incubate in a $37^{\circ} \mathrm{C}$ humidified incubator to allow floating cellular clusters (cardioblasts) to form for 4-5 days.

\section{Beating Cardiomyocyte Phenotype Maturation in Adhesive Culture}

1. Pool the media containing floating cardioblasts together in a $50 \mathrm{ml}$ conical tube. Centrifuge at $1400 \mathrm{rpm}$ for $5 \mathrm{~min}$. Aspirate the old media as much as you can and add equal amount of fresh hESC cardiac differentiation media containing 10 mM NAM.

2. Pipette up and down to mix floating cardioblasts and aliquot $4 \mathrm{ml} /$ well to 6 -well plates. Transfer the plates to a $37^{\circ} \mathrm{C}$ humidified incubator to allow cardioblasts to attach overnight.

3. Replace hESC cardiac differentiation media containing $10 \mathrm{mM}$ NAM every other day. 
4. At day 8 , replace with $\mathrm{hESC}$ cardiac differentiation media without NAM, and continue to replace HESC cardiac differentiation media every other day. Beating cardiomyocytes will begin to appear in about 1-2 weeks of continuous cultivation after withdrawal of NAM and increase in numbers with time, and could retain strong and rhythmic contractions for over 3 months.

\section{Representative Results:}

Nicotinamide (NAM) is rendered sufficient to induce hESCs maintained in the defined culture system to transition from pluripotency exclusively to a cardiomesodermal phenotype (Fig. 2B). Upon exposure of undifferentiated hESCs to NAM, all the cells within the colony will undergo morphology changes to large differentiated cells that down-regulate the expression of Oct- 4 and begin to express the cardiac specific transcription factor (Csx) Nkx2.5 and a-actinin, consistent with a cardiomesoderm phenotype (Fig. 2B). These differentiated cells will continue to multiply and the colonies increase in size. Increased intensity of Nkx2.5 will be usually observed in areas of the colonies where cells begin to pile up (Fig. 2B). After detached, the NAM-treated hESCs will form floating cellular clusters (cardioblasts) in a suspension culture to continue the cardiac differentiation process. After permitting the cardioblasts to attach and continuing to treat with NAM for 1 week, beating cardiomyocytes will begin to appear in about 1-2 weeks of continuous cultivation after withdrawal of NAM with a drastic increase in efficiency as compared to spontaneous multi-lineage differentiation of hESCs without treatment over the same time period (Fig. 2C). Cells within the beating cardiomyocyte clusters will express markers characteristic of cardiomyocytes, including Nkx2.5 and a-actinin (Fig. 2C). The contractions of the beating cardiomyocytes were confirmed by electrical profiles to be strong, rhythmic, well-coordinated, and well-entrained, with regular impulses reminiscent of the p-QRS-T-complexes seen from body surface electrodes in clinical electrocardiograms (Fig. 2C, also see the Video). The cardiomyocytes could retain their strong contractility for over 3 months.

A

Multi-Lineage Differentiation of Pluripotent Cells

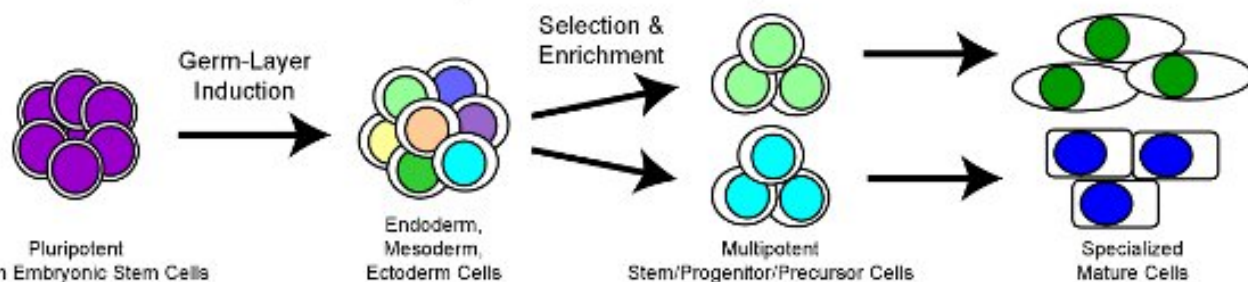

Human Embryonic Stem Cells

$$
\text { Ectoderm Cells }
$$

Stem/Progenitor:Precursor Cells

Lineage-Specific Differentiation of Pluripotent Cells by Small Molecule Induction

B

Lineage Specific

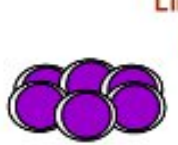

Pluripotent

Human Embryonic Stem Cells

in Defined Culture

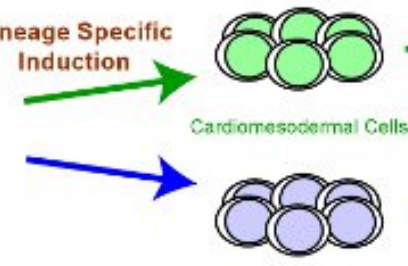

Neuroectodermal Cells

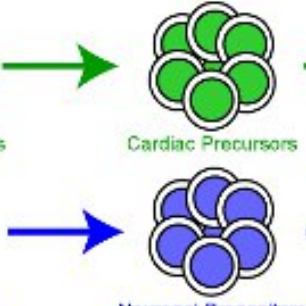

Neuronal Progenitors

Multipotent

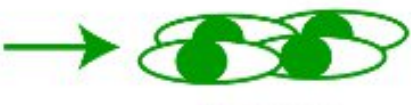

Cardiomyocytes

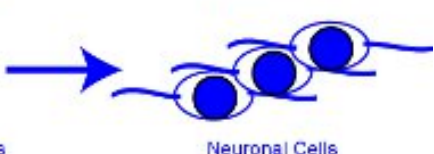

Specialized Mature Cells

Figure 1. Overall schemes of conventional approach versus small-molecule-induction approach for differentiation of human pluripotent stem cells towards specialized functional cells. (A) A schematic of conventional approach using multi-lineage inclination of human pluripotent stem cells through spontaneous germ layer differentiation. (B) A schematic of well-controlled efficient induction of human pluripotent stem cells exclusively to a particular clinically-relevant lineage by simple provision of small molecules. 
A

\begin{tabular}{|c|c|c|c|c|}
\hline $\begin{array}{l}\text { Seeding in } \\
\text { Defined Culture }\end{array}$ & $\begin{array}{l}\text { Cardiac Induction } \\
\text { in Defined Culture }\end{array}$ & $\begin{array}{l}\text { Suspension } \\
\text { Culture }\end{array}$ & \\
\hline hESC Nedia + bFGF & hESC Media + bFGF + NAM & hESC Modis & \multicolumn{2}{|c|}{$\begin{array}{c}\text { Cardiac Diflerentiation } \\
\text { Media + NAM }\end{array} \mid \begin{array}{c}\text { Carduration in Attachment } \\
\text { Differentiation Modia }\end{array}$} \\
\hline |Undifferentiated hESCs & Cardiomesodemal Cells & Cardioblasts & & Beating Cardiomyocylos \\
\hline ay $1 \quad$ Day & & \multicolumn{3}{|r|}{ Day 35} \\
\hline
\end{tabular}

B
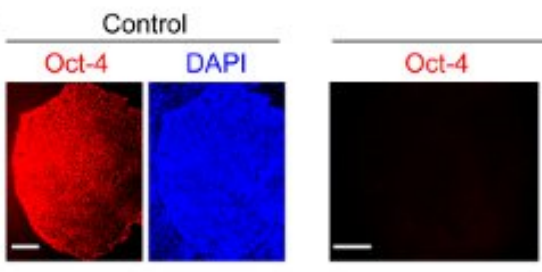

NAM

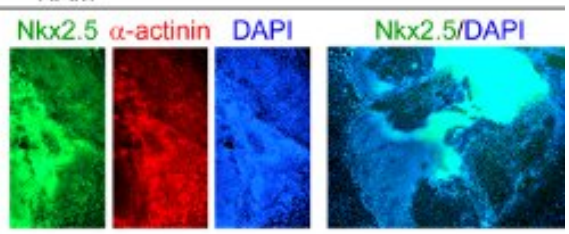

C

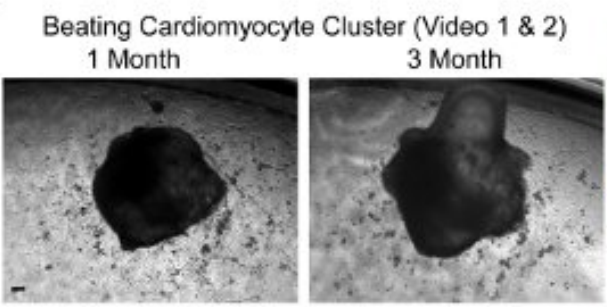

Contracting Cardiac Muscle (Video 3 \& 4)
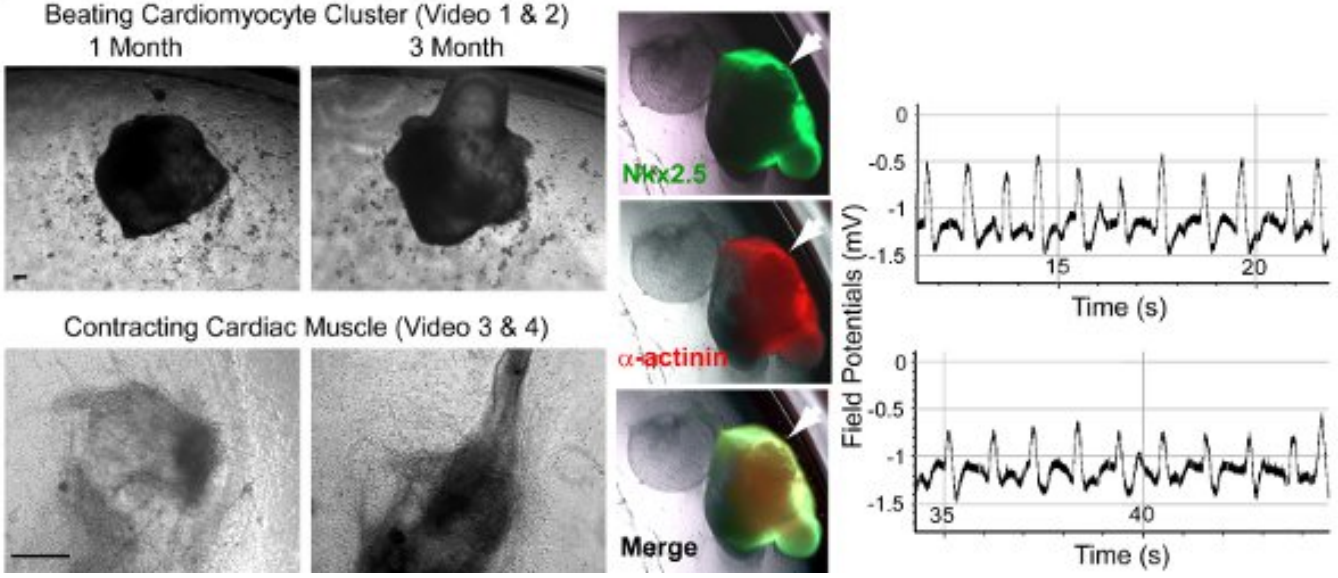

Figure 2. Nicotinamide induces cardiac lineage specification direct of pluripotency under defined conditions and progression towards beating cardiomyocytes. (A) Schematic depicting of the protocol time line of directed cardiac differentiation of $\mathrm{hESCs}$. (B) Upon exposure of undifferentiated hESCs to Nicotinamide (NAM) under the defined culture system, large differentiated Oct-4 (red) negative cells within the colony began to emerge, as compared to mock-treated (DMSO) hESCs as the control. NAM-induced Oct-4-negative cells began to express $\mathrm{Nkx2.5} \mathrm{(green)} \mathrm{and} \alpha$-actinin (red), consistent with early cardiac differentiation. Progressively increased intensity of Nkx2.5 was usually observed in areas of the colony where cells began to pile up. All cells are indicated by DAPI staining of their nuclei (blue). (C) NAM-induced cardiaccommitted hESCs yielded beating cardiomyocytes with a drastic increase in efficiency, as assessed by the cellular clusters that displayed rhythmic contractions (see electrophysiological profile and the Videos), and immunopositive for Nkx2.5 (green) and a-actinin (red). Phase images of representative large beating cardiomyocyte clusters and higher power images of representative contracting cardiac muscles are shown (also see corresponding videos). Arrows indicate the large beating cardiomyocyte cluster used for electrophysiological recording. Electrophysiological profile of the beating cardiomyocytes shows regular, entrained, rhythmic impulses reminiscent of the p-QRS-T-complexes seen in clinical electrocardiograms. Scale bars: $0.1 \mathrm{~mm}$.

Videos: Contracting cardiomyocytes differentiated from NAM-induced hESCs. Videos 1 and 2 show representative large beating cardiomyocyte clusters in about 1 and 3 month after attachment. Video $\mathbf{3}$ and $\mathbf{4}$ show representative contracting cardiac muscles at higher power. Video 5 shows a typical small beating cardiomyocyte cluster spontaneously differentiated from hESCs without NAM treatment as control.

Click here to watch Video 1.

Click here to watch Video 2.

Click here to watch Video 3.

Click here to watch Video 4.

Click here to watch Video 5.

\section{Discussion}

One of the major challenges for both developmental study and clinical translation has been how to channel the broad differentiation potential of pluripotent human stem cells to a desired phenotype efficiently and predictably. Although such cells can differentiate spontaneously in vitro into cells of all germ layers by going through a multi-lineage aggregate stage, in hESC-derived multi-lineage aggregates (embryoid bodies), only a very small fraction of cells $(<2 \%)$ spontaneously differentiate into cardiomyocytes ${ }^{13-15}$ (Fig. 1A). Following immunoselection, the enriched populations of cardiomyocytes were able to function as biological pacemakers to rescue the function of a damaged myocardium mechanically and electronically following injection into the heart of animal models ${ }^{13}$. In rodent infarcted models, engrafted hESC-derived cardiac progenies were able to survive and mature up to 12 weeks, and partially remuscularize the injured heart and improve the contractile function ${ }^{14,15}$. However, the inefficiency in generating human cardiac-committed cells through multi-lineage differentiation of pluripotent cells and the high risk of tumorigenicity following transplantation have hindered further clinical translation. Developing strategies to channel the wide differentiation 
potential of pluripotent hESCs exclusively and predictably to a cardiac phenotype is vital to harnessing the power of hESC biology in the heart field. In order to achieve uniformly conversion of human pluripotent stem cells to a particular lineage, we employed a defined culture system capable of insuring the proliferation of undifferentiated hESCs to identify conditions for well-controlled efficient induction of pluripotent hESCs exclusively to a particular clinically-relevant lineage by simple provision of small molecules (Fig 1B). We found that nicotinamide induced cardiac-lineage commitment direct from pluripotent hESCs under defined culture that further progressed to beating cardiomyocytes with high efficiency (Fig. 2). Nkx2.5 is an evolutionally conserved homeobox transcription factor indispensable for normal cardiac development and mutations of the gene are associated with human congenital heart disease (CHD), the most common human birth defect ${ }^{16}$. Expression of Nkx2.5 is the earliest marker for heart precursor cells in all vertebrates so far examined and is essential for proper cardiac septation and formation/ maturation of electrical conduction system ${ }^{16}$. In vertebrates, the onset and pattern of early Nkx2.5 expression roughly coincide with the timing and area of cardiac specification in early embryogenesis, and Nkx2.5 gene continues to be expressed through development in the heart ${ }^{16}$. In our hESC model, NAM appeared to trigger the cardiac induction direct from pluripotent hESCs by promoting the expression of cardiac-specific transcription factor Nkx2.5 in a process that might emulate the specification of cardiomesoderm from the pluripotent epiblast in human embryonic cardiogenesis. Future studies will reveal genetic and epigenetic control molecules in human heart development as alternatives, which may pave the way for small molecule-mediated direct control and modulation of hESC pluripotent fate when deriving clinically-relevant lineages for regenerative therapies. Without NAM treatment, $<2 \% \mathrm{hESCs}$ will undergo spontaneous differentiation into beating cardiomyocytes ${ }^{12-15}$. With NAM treatment, we have been able to generate $>95 \%$ embryonic cardiac precursors and $>50 \%$ beating cardiomyocytes from $\mathrm{hESCs}$ maintained under a define culture in a process that might emulate human embryonic heart development ${ }^{12}$. Recently, known cardiac-fate determining genes have been used to transdifferentiate mouse fibroblasts into post-natal beating cardiomyocytes with a low efficiency of < $0.5 \%{ }^{17}, 18$. However, reprogrammed somatic cells have historically been associated with abnormal gene expression and accelerated senescence with impaired therapeutic utility ${ }^{19-21}$. Finally, the protocol we established here is limited to pluripotent hESCs derived from the inner cell mass (ICM) or epiblast of the human blastocyst ${ }^{4,5}$, may not apply to other pluripotent cells, including animal-originated ESCs, ESCs derived from earlier morula (eight-cell)-stage embryos ${ }^{22}$, and artificially reprogrammed cells ${ }^{23}$.

\section{Disclosures}

The authors declare competing interests. XHP is the founder of Xcelthera. XHP and EYS have intellectual properties related to hESCs.

\section{Acknowledgements}

XHP has been supported by National Institute of Health (NIH) grants from National Institute on Aging (NIHK01AG024496) and The Eunice Kennedy Shriver National Institute of Child Health and Human Development (NIHR21HD056530).

\section{References}

1. Jawad, H., Ali, N.N., Lyon, A.R., Chen, Q.Z., Harding, S.E., \& Boccaccini, A.R. Myocardial tissue engineering: a review. J. Tissue. Eng. Regen. Med. 1, 327-42 (2007).

2. Passier, P., van Laake, L.W., \& Mummery, C.L. Stem-cell-based therapy and lessons from the heart. Nature. 453, 322-329 (2008)

3. Zhu, W. Z., Hauch, K. D., Xu, C., \& Laflamme, M. A. Human embryonic stem cells and cardiac repair. Transplant Rev. 23, 53-68 (2009).

4. Parsons, X. H., Teng, Y. D., \& Snyder, E. Y. Important precautions when deriving patient-specific neural elements from pluripotent cells. Cytotherapy. 11, 815-824 (2009).

5. Thomson, J. A., Itskovitz-Eldor, J., Shapiro, S. S., Waknitz, M. A., Swiergiel. J. J., Marshall, V. S., \& Jones, J. M. Embryonic stem cell lines derived from human blastocysts. Science. 282, 1145-1147 (1998).

6. Aubry, L., Bugi, A., Lefort, N., Rousseau, F., Peschanski, M., \& Perrier, A.L. Striatal progenitors derived from human ES cells mature into DARPP32 neurons in vitro and in quinolinic acid-lesioned rats. Proc. Natl. Acad. Sci. U.S.A. 105, 16707-16712 (2008).

7. Roy, N.S., Cleren, C., Singh, S.K., Yang, L., Beal, M.F., \& Goldman, S.A. Functional engraftment of human ES cell-derived dopaminergic neurons enriched by coculture with telomerase-immortalized midbrain astrocytes. Nature Medicine. 12, 1259-1268 (2006).

8. Wernig, M., Zhao, J.P., Pruszak, J., Hedlund, E., Fu, D., Soldner, F., Broccoli, V., Constantine-Paton, M., Isacson, O., \& Jaenisch, R. Neurons derived from reprogrammed fibroblasts functionally integrate into the fetal brain and improve symptoms of rats with Parkinson's disease. Proc. Natl. Acad. Sci. U.S.A. 105, 5856-5861 (2008).

9. Richards, M., Fong, C., Chan, W., Wong, P., \& Bongso, A. Human feeders support prolonged undifferentiated growth of human inner cell masses and embryonic stem cells. Nature. Biotechnol.. 20, 933-936 (2002).

10. Xu, C., Inokuma, M.S., Denham, J., Golds, K., Kundu, P., Gold, J.D., \& Carpenter, M. Feeder-free growth of undifferentiated human embryonic stem cells. Nature Biotechnol. 19, 971-974 (2001).

11. Xu, R.H., Peck, R.M., Li, D.S., Feng, X., Ludwig, T., \& Thomson, J.A. Basic FGF and suppression of BMP signaling sustain undifferentiated proliferation of human ES cells. Nature Methods. 2, 185-190 (2005).

12. Parsons, X.H., Teng, Y.D., Moore, D.A., \& Snyder, E.Y. Patents on technologies of human tissue and organ regeneration from pluripotent human embryonic stem cells. Recent Patents on Regenerative Medicine. 1, 142-163 (2011).

13. Kehat, I., Khimovich, L., Caspi, O., Gepstein, A., Shofti, R., Arbel, G., Huber, I., Satin, J., Itskovitz-Eldor, J., \& Gepstein, L. Electromechanical integration of cardiomyocytes derived from human embryonic stem cells. Nat. Biotechnol. 22, 1282-1289 (2004).

14. Laflamme, M.A., Chen, K.Y., Naumova, A.V., Muskheli, V., Fugate, J.A., Dupras, S.K., Reinecke, H., Xu, C., Hassanipour, M., Police, S., O'Sullivan, C., Collins, L., Chen, Y., Minami, E., Gill, E.A., Ueno, S., Yuan, C., Gold, J., Murry, C. E. Cardiomyocytes derived from human embryonic stem cells in pro-survival factors enhance function of infracted rat hearts. Nat. Biotechnol. 25, 1015-1024 (2007).

15. Caspi, O., Huber, I., Kehat, I., Habib, M., Arbel, G., Gepstein, A., Yankelson, L., Aronson, D., Beyar, R., Gepstein, L. Transplantation of human embryonic stem cell-derived cardiomyocytes improves myocardial performance in infarcted rat hearts. J. Am. Coll. Cardiol. 50, 1884-1893 (2007).

16. Akazawa, H., \& Komuro, I. Cardiac transcription factor Csx/Nkx2-5: Its role in cardiac development and diseases. Pharmacol. Ther. 107, 252-268 (2005). 
17. Leda, M., Fu, J.D., Delgado-Olguin, P., Vedantham, V., Hayashi, Y., Bruneau, B.G., \& Srivastava, D. Direct reprogramming of fibroblasts into functional cardiomyocytes by defined factors. Cell. 142, 375-386 (2010).

18. Efe, J.A., Hilcove, S., Kim, J., Zhou, H., Ouyang, K., Wang, G., Chen, J., \& Ding, S. Conversion of mouse fibroblasts into cardiomyocytes using a direct reprogramming strategy. Nat. Cell. Biol. 13, 215-222 (2011).

19. Kim, K., Doi, A., Wen, B., Ng, K., Zhao, R., Cahan, P., Kim, J., Aryee, M.J., Ji, H., \& Ehrlich, L.I. Epigenetic memory in induced pluripotent stem cells. Nature. 467, 285-290 (2010).

20. Gore, A., Li, Z., Fung, H.L., Young, J.E., Agarwal, S., Antosiewicz-Bourget, J., Canto, I., Giorgetti, A., Israel, M.A., Kiskinis, E., et al. Somatic coding mutations in human induced pluripotent stem cells. Nature. 471, 63-67 (2011).

21. Feng, Q., Lu, S.J., Klimanskaya, I., Gomes, I., Kim, D., Chung, Y., Honig, G.R., Kim, K.S., \& Lanza, R. Hemangioblastic derivatives from human induced pluripotent stem cells exhibit limited expansion and early senescence. Stem Cells. 28, 704-712 (2010).

22. Klimanskaya, I., Chung, Y., Becker, S., Lu, S.-J., \& Lanza, R. Derivation of human embryonic stem cells from single blastomeres. Nat. Protocols. 2, 1963-1972 (2007).

23. Park, I.H., Zhao, R., West, J.A., Yabuuchi, A., Huo, H., Ince, T.A., Lerou, P.H., Lensch, M.W., \& Daley, G.Q. Reprogramming of human somatic cells to pluripotency with defined factors. Nature. 451, 141-146 (2008). 